\title{
UK sends double message in science spending plans
}

London. Despite the enthusiastic noises in last year's science white paper, total government support for civilian science and technology in the United Kingdom is expected to fall by more than 8 per cent over the next three years, according to figures published in London this week.

The biggest fall in spending will be in the Department of Trade and Industry (DTI). Following its decision to concentrate on direct support for technology transfer, the DTI's spending on science and technology is due to fall from $£ 423.5$ million in the current year to $£ 271.2$ million in the year 1996-97, in real terms a drop of 42 per cent.

In contrast, the Department of Health will see its research budget grow by 11 per cent in real terms. In line with policies that have already

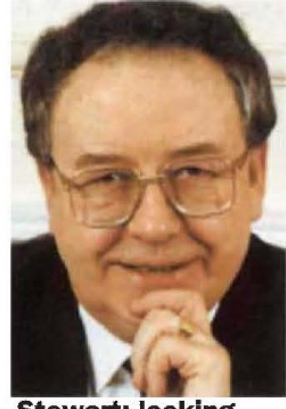
Stewart: looking for co-ordination. been announced, total spending by the six research councils remains virtually constant.

The figures are contained in the first edition of a new publication, Forward Look, which is to be put together annually by the Cabinet Office's Office of Science and Technology (OST). Based on individual departments' spending plans, the publication replaces the previous annual reviews of (past) expenditure on research and development.

According to the white paper, the preparation of the Forward Look is intended to allow the OST to check on the extent to which department's are fulfilling the government's commitments to steer science towards the twin goals of wealth creation and improving the quality of life.

"In its way, this document is almost as important as the white paper," says Bill Stewart, the government's chief scientific adviser, who was largely responsible for its preparation. "This is the first time that different departments have put down in a single document their thoughts about their future spending on research."

Forward Look points out the government's success in boosting some areas of research, and in reining in expenditure in other areas. Spending on defence research, for example, is planned to fall "by about one third in real terms" by the end of the century.

Officials emphasize that two elements are likely to play a greater role in the preparation of similar documents in future years. One is the input from the recently-launched Technology Foresight exercise, expected to provide a consensus of the major fields in which government research spending needs to be concentrated. The second is the inclusion of a number of "output" measures which, says Stewart, will show how far departments have taken on board the strategy outlined in the white paper.

In his introduction to the document, William Waldegrave, the cabinet minister responsible for science, admits that, without such input, this year's document is "inevitably incomplete." Its main message in its current form, says Stewart, is to show how the promises to be made in the white paper are likely to be met.

But it is another promise - that was made last year by Prime Minister John Major in an address to the Parliamentary and Scientific Committee - which is also likely to be measured against the details of the Forward Look in future years. This was the commitment that the Conservative government would take steps to make good its neglect of science in the past.

That promise is likely to be measured, at least by the scientific community, primarily in financial terms. This year's document points out that the main reductions in government support for science are the result of cuts in defence and nuclear research. But the detailed figures also show that is not the whole story.

David Dickson

\section{'Broad approach' needed to innovation policy}

London. An all-party Parliamentary committee has urged the government to broaden its efforts to stimulate innovation in industry away from merely concentrating on the health of the country's science base.

In a report published in London on Monday the House of Commons Science and Technology Committee says that the task of creating a climate in which innovation can flourish cannot be left to the OST alone, but needs additional support.

"It will not succeed unless all depart-

\section{Fermilab remains cautious on top quark 'discovery'}

Washington. Scientists at the Fermi National Laboratory (Fermilab) in Illinois this week unveiled strong evidence for the existence of the elusive fundamental particle known as the top quark. But they stopped short of claiming its discovery.

The physicists say that the particle recorded by the Collider Detector at Fermilab (CDF) has a mass of $174 \pm 17 \mathrm{GeV}$, and that the statistical odds that the events pointing to its existence occurred by chance are 1-in400.

"That may sound like a small probability, but for something as fundamental as the top quark, we'd want more statistical significance to claim discovery," says Bill Carithers of the Lawrence Berkeley Laboratory in California. Carithers and Mel Shochet of the University of Chicago are the elected chief spokesmen for the 440 scientists working on the CDF detector at the laboratory.

Carithers says that evidence collected about the top quark from 10 months of watching protons collide with antiprotons is "very, very consistent" with recent theoretical predictions of what the top quark should look like.

If its existence is confirmed, the particle - which has a mass 200 times that of a proton and decays in between $10^{-25}$ seconds - joins bottom, up, down, strangeness and charm to complete the family of quarks predicted by the Standard Model of particle physics (see page 805 ).

Speaking from the office in Texas where he is now temporarily engaged closing down the Superconducting Super Collider, Fermilab director John Peoples says that he welcomed the breakthrough. But he declined to speculate on its likely impact on the fraught matter of high-energy physics funding. "I'm too naive to read the politics," said Peoples. "But from the scientific standpoint, this is good for the field." He added that the results would be useful to help work out how Fermilab's detectors needed to be upgraded to find out more about the top quark.

The CDF team, which represents 39 institutions in the United States, Italy, Canada, Taiwan and Japan, looked for two distinct modes of top quark decay in their study. With the first mode, they detected two events over the ten months, where 0.6 such events would be expected as "background".

Looking at the second mode of decay, the team found 6 events, against an expected background of 2.3 , with one technique, and 7 against 3.1 with another. "When you combine these, the probability that the observed events were just a fluctuation is 1 in 400 ," says Carithers. The CDF team has submitted a 200-page paper on its results to Physical Review $D$.

Colin Macilwain 